\title{
Evaluation of Ki67 Expression in Relation to Tumor Stage and Fuhrman Nuclear Grade of Renal Cell Carcinoma and MUC1 Expression in Clear Cell Renal Cell Carcinoma
}

\author{
Sarumathy Ganesan ${ }^{1}$, Prathiba Arumugam², Nithya Ilanchezhian³, Saraswathi Manickam4 \\ 1,4 Department of Pathology, Sri Muthukumaran Medical College and Research Institute, \\ Chennai, Tamil Nadu, India. ${ }^{2}$ Department of Pathology, Panimalar Medical College Hospital and \\ Research Institute, Chennai, Tamil Nadu, India. ${ }^{3}$ Department of Pathology, Government \\ Vilupuram Medical College and Hospital, Mundiyampakkam, Tamil Nadu, India.
}

\section{ABSTRACT}

\section{BACKGROUND}

Renal cell carcinoma (RCC) is the most common malignant renal tumour in adults. Prognosis of RCC depends on various factors like tumour stage, nuclear grade and histological type. For planning adjuvant therapy, accurate prediction of prognosis is mandatory. In many studies, ki67 and MUC1 has shown to be of prognostic significance and immunohistochemical expression of these two markers plays an important role in determining the prognosis of RCC. The purpose of this study was to evaluate the Ki67 expression in histologically confirmed cases of RCC and MUC1 expression in clear cell renal cell carcinoma, and to correlate them with the stage and Fuhrman nuclear grade of the tumour, in order to determine their role as prognostic markers in RCC.

\section{METHODS}

This study was a retrospective study. A total of 50 specimens of renal cell carcinoma were studied. The specimens were total and partial nephrectomy done in the department of urology for a period of 3 years. Expression of Ki67 and MUC1 in RCC were studied by immunohistochemistry (IHC). Statistical analysis was performed and $\mathrm{P}$ value $<0.05$ was considered significant.

\section{RESULTS}

Out of 50 RCC studied, Ki67 labelling index $\geq 15 \%$ was found in 35 cases. For MUC1, immunoreactivity of more than $10 \%$ of tumor cell was found in 28/34 of clear cell RCC. In this study, Ki67 labelling index showed statistically significant expression with the stage of tumor and the nuclear grade. MUC1 expression also showed significant correlation with nuclear grade and stage of clear cell RCC.

\section{CONCLUSIONS}

High Ki67 labelling index in renal cell carcinoma is seen to correlate with higher nuclear grade and stage of tumor. High level expression with circumferential staining pattern of MUC1 is seen in high grade tumours with increased risk of metastasis. So MUC1 and Ki67 can be considered as a marker of prognosis of RCC.
Corresponding Author: Dr. Sarumathy Ganesan, Department of Pathology, Sri Muthukumaran Medical College and Research Institute, Tamil Nadu, India. E-mail: gsarumathy111@gmail.com

\section{DOI: $10.14260 /$ jemds $/ 2021 / 555$}

How to Cite This Article: Ganesan S, Arumugam P, Ilanchezhian N, et al. Evaluation of Ki67 expression in relation to tumor stage and fuhrman nuclear grade of renal cell carcinoma and MUC1 expression in clear cell renal cell carcinoma. J Evolution Med Dent Sci 2021;10(33):2718-2722, $10.14260 /$ jemds/2021/555

Submission 18-05-2021, Peer Review 12-07-2021, Acceptance 18-07-2021, Published 16-08-2021.

Copyright (C) 2021 JEMDS. This is an open access article distributed under Creative Commons Attribution License [Attribution 4.0 International (CC BY 4.0)]

\section{KEY WORDS}

Renal Cell Carcinoma, Immunohistochemistry, Ki67, MUC1 


\section{BACKGROUND}

Renal cell carcinoma is the most common malignant tumour of the kidney. It accounts for $2.5 \%$ of all cancers ${ }^{1}$ among the urinary system malignancy and RCC ranks third ${ }^{2}$ after prostate and bladder tumour. Worldwide, RCC is the $9^{\text {th }}$ most common malignancy in men and $14^{\text {th }}$ in women. The case fatality rate was found to be low in highly developed countries than with low or medium level of socio-economic development. $^{3}$ Most of the renal cell carcinoma cases are sporadic and $2 \%$ to $3 \%$ are familial. ${ }^{4}$ Symptoms of RCC includes the triad of hematuria, palpable abdominal mass and flank pain. Clear cell RCC is the most common type, representing $70 \%$ of all RCCs, followed by papillary RCC which accounts for $10 \%-15 \%$, and then chromophobe RCC. ${ }^{2}$ Different histological subtypes of RCC and tumours with the same grade and stage exhibit a wide variation in biological behaviour and prognosis. RCC is resistant to radiotherapy and chemotherapy. Nearly $40 \%$ of RCC patients die because of disease progression. ${ }^{5}$ At the time of diagnosis, approximately $30 \%$ have metastasis and $20 \%$ of patients develop metastasis even after curative treatment for localised disease. ${ }^{6}$ Several clinical and pathologic factors affecting the prognosis have been reported in many studies. Prognostic factors are useful in determining the clinical and biological behaviour of RCC. ${ }^{2}$ Patient presenting in the early stage of the disease were cured by surgery but those presenting with the metastasis are almost incurable. 4 Patients with poor prognosis should be identified early for timely initiation of target therapy. Study on molecular tumour markers expression can advance our understanding of the pathogenesis, diagnosis and treatment of RCC. ${ }^{7}$

Ki67 is a marker of active cell proliferation. Ki67 is absent in resting cells (G0 phase) and is present during all active phases of cell cycle (i.e. G1, S, G2 and mitosis 6 ). In many studies, it has been reported that Ki67 expression predicts poor prognosis in solid tumours like breast cancer, cervical cancer, prostate cancer, glioma and hepatocellular carcinoma. ${ }^{8}$ Proliferative activity of tumour cells can be determined by this marker. Ki67 was found to correlate with nuclear grade and it can be used for predicting the prognosis of RCC.

MUC1 is a large trans-membrane glycoprotein and is found on the apical surface of glandular cells and duct epithelial cells. In kidney, MUC1 was found on the luminal surface of distal tubule epithelium and collecting duct epithelium. ${ }^{9}$ Tumor cells show loss of polarity and there is a switch from apical to circumferential staining. Aberrant de novo expression or over expression of MUC1 is supposed to play a role in the invasion and metastasis because of reduced cell adhesion. ${ }^{10}$ In renal cell carcinoma, MUC1 is over expressed in clear cell RCC and its expression is found to be associated with the Fuhrman nuclear grade and tumour progression. Immunohistochemistry was performed with Ki67 and its expression was correlated with tumor stage and nuclear grade. MUC1 expression was also evaluated in clear cell RCC, with respect to its role in predicting the prognosis.

\section{Objectives}

The objective of this study was to study the clinicopathological features of renal cell carcinoma, to evaluate the Ki67 expression in renal cell carcinoma in relation to the histological types, tumor stage and nuclear grade, and to evaluate the MUC1 expression in clear cell RCC in relation to the tumor stage and nuclear grade.

Aim of this study was to evaluate the MUC1 and Ki67 expression as markers of prognosis in RCC.

\section{METHODS}

This study was a retrospective study. In our department, proportion of RCC cases among adult malignancies we received was $3 \%$. Sample size obtained using Danial's sample size formula was 45 . RCC specimens received during this study period was 50 and all the specimens were included in the study. The specimens were total and partial nephrectomy done in the department of urology of tertiary care institute for a period of 3 years from January 2011 to January 2014.

\section{Inclusion Criteria}

All histologically confirmed renal cell carcinoma specimens according to world health organization (WHO) classification of tumours of the urinary system and male genital organs were included. ${ }^{11}$

\section{Exclusion Criteria}

1. Renal biopsy specimens

2. Renaltumours other than renal cell carcinoma

\section{Ethical Approval}

Permission of the Institutional Ethics Committee was obtained.

\section{Data Collection}

Clinical details such as age, gender, laterality, type of procedure done were collected for renal cell carcinoma specimens received during the period of study. Specimen were fixed in $10 \%$ neutral buffered formalin. Grossing and reporting were done according to cancer protocol (CAP). Haematoxylin and eosin stained sections were prepared from paraffin tissue blocks. All the cases reported as renal cell carcinoma were selected. Parameters like histological type, Fuhrman nuclear grading, necrosis, sarcomatoid differentiation, capsular infiltration, ureter invasion, renal vessel invasion, lymph node involvement, distant metastasis and staging were performed. Histological subtype of renal cell carcinoma was done according to WHO classification of tumours of the urinary system and male genital organs. ${ }^{11}$ Nuclear grading was done according to the Fuhrman nuclear grading system. Pathological staging was done according to American Joint Committee on cancer 2010.12

\section{Immunohistochemical Staining for Ki67 and MUC1}

Ki67 immunohistochemistry was done in all RCC cases and MUC1immunohistochemistry was performed on clear cell RCC cases. IHC was performed using monoclonal mouse clone 
antibody-DAKO for detection of Ki67 and monoclonal rabbit antibody-PATHINSITU for detection of MUC1. Normal kidney with distal convoluted tubules and collecting ducts was taken as positive control for MUC1, and tonsil was taken as positive control for Ki67. Negative control was done by omitting the primary antibody.

\section{Evaluation of IHC Staining}

In Ki67 immunoreactivity, nucleus will be stained as dark brown in colour. Number of cells positive are counted and expressed as percentage. Cut off value was $15 \%$ according to Mehdi MZ et al. ${ }^{13}$

A positive cell was considered, when MUC1 showed membranous, cytoplasmic or both staining patterns. Number of cells positive are counted and expressed in percentage. Immunoreactivity was graded as follows:

- no reactivity

- 1 - less than $10 \%$ of cancer cells positive

- $2-10-25 \%$ positive

- 3 - $25-50 \%$ positive

- $4-50-75 \%$ positive

- 5 - $75-90 \%$ positive

- 6 - More than $90 \%$ positive.

For statistical analysis, sample showing more than $10 \%$ immunoreactivity was considered as positive. ${ }^{9}$

\section{Statistical Analysis}

The statistical analysis was performed using Statistical Package for Social Science (SPSS software version 15.5) which consisted computing the frequency counts and percentages for qualitative variables and mean for the quantitative variables. Chi square test was used to analyse the association between the different variables in the study and the $P$ value below 0.05 was considered significant.

\section{RESULTS}

Totally 50 cases of renal cell carcinoma were studied with histopathology and immunohistochemistry. The cases were found in the age group of 28 - 80 years. The most common age group affected were 41 - 50 years. Males are more commonly affected and they account for $74 \%$ of cases. Right kidney (68\%) was affected more commonly than left kidney. $60 \%$ of patients had history of smoking. $61 \%$ patients were hypertensive. Stage 1 was the most common stage at presentation and it accounts for $34 \%$ of cases, followed by 26 $\%$ cases in stage $2,26 \%$ cases in stage 3 and $14 \%$ cases in stage $4.20 \%$ of cases were nuclear grade $1,28 \%$ of cases were nuclear grade $2,32 \%$ of cases were nuclear grade 3 and $20 \%$ of cases were nuclear grade 4 (Table 1 ).

\section{Distribution of Renal Cell Carcinoma Based on Histological Types and Expression of Ki67 in Various Types}

Among 50 cases of renal cell carcinoma studied, clear cell carcinoma was the most common type (68\%) followed by papillary RCC (16\%), chromophobe RCC (4 \%) and unclassified type (12\%).For clear cell RCC, Ki67 labelling index was $\geq 15 \%$ in $67.6 \%$ of cases while the same is $62.5 \%$ for papillary RCC and $50 \%$ for chromophobe RCC (Figure 1); in unclassified type, all cases had labelling index $\geq 15 \%$. There was no significant association between Ki67 labelling index and histological type $(\mathrm{P}=0.35)$.

\begin{tabular}{|c|c|c|c|}
\hline & & Frequency & Percentage \% \\
\hline \multirow{4}{*}{ Stage of tumor } & Stage I & 17 & 34 \\
\hline & Stage II & 13 & 26 \\
\hline & Stage III & 13 & 26 \\
\hline & Stage IV & 7 & 14 \\
\hline \multirow{4}{*}{$\begin{array}{l}\text { Types of renal cell } \\
\text { carcinoma }\end{array}$} & Clear cell RCC & 34 & 68 \\
\hline & Papillary RCC & 8 & 16 \\
\hline & Chromophobe RCC & 2 & 4 \\
\hline & Unclassified & 6 & 12 \\
\hline \multirow{4}{*}{$\begin{array}{c}\text { Fuhrman nuclear } \\
\text { grading }\end{array}$} & Grade 1 & 10 & 20 \\
\hline & Grade 2 & 14 & 28 \\
\hline & Grade 3 & 16 & 32 \\
\hline & Grade 4 & 10 & 20 \\
\hline
\end{tabular}
Fuhrman Nuclear Grade of Renal Cell Carcinoma

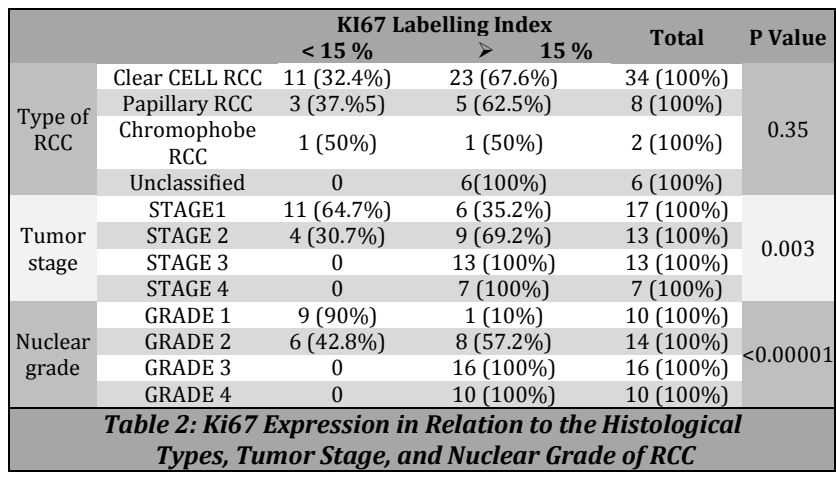

\begin{tabular}{|c|c|c|c|c|c|c|c|c|c|c|}
\hline & & \multicolumn{7}{|c|}{ MUC1 Grade } & \multirow[b]{2}{*}{ Total } & \multirow{2}{*}{$P$ Value } \\
\hline & & 0 & 1 & 2 & 3 & 4 & 5 & 6 & & \\
\hline \multirow{4}{*}{$\begin{array}{l}\text { Tumor } \\
\text { stage }\end{array}$} & Stage1 & 2 & 4 & 2 & 3 & 0 & 0 & 1 & 12 & \multirow{4}{*}{0.006} \\
\hline & Stage 2 & 0 & 0 & 1 & 5 & 4 & 1 & 0 & 11 & \\
\hline & Stage 3 & 0 & 0 & 1 & 0 & 1 & 3 & 2 & 7 & \\
\hline & Stage 4 & 0 & 0 & 0 & 0 & 1 & 3 & 0 & 4 & \\
\hline \multirow{4}{*}{$\begin{array}{l}\text { Nuclear } \\
\text { grade }\end{array}$} & Grade 1 & 2 & 3 & 3 & 1 & 0 & 0 & 0 & 9 & \multirow{4}{*}{0.0002} \\
\hline & Grade 2 & 0 & 1 & 1 & 6 & 2 & 0 & 0 & 10 & \\
\hline & Grade 3 & 0 & 0 & 0 & 1 & 1 & 7 & 1 & 10 & \\
\hline & Grade 4 & 0 & 0 & 0 & 0 & 1 & 2 & 2 & 5 & \\
\hline \multicolumn{11}{|c|}{$\begin{array}{l}\text { Table 3. MUC1 Expression in Relation to the } \\
\text { Stage and Nuclear Grade of Clear Cell RCC }\end{array}$} \\
\hline
\end{tabular}

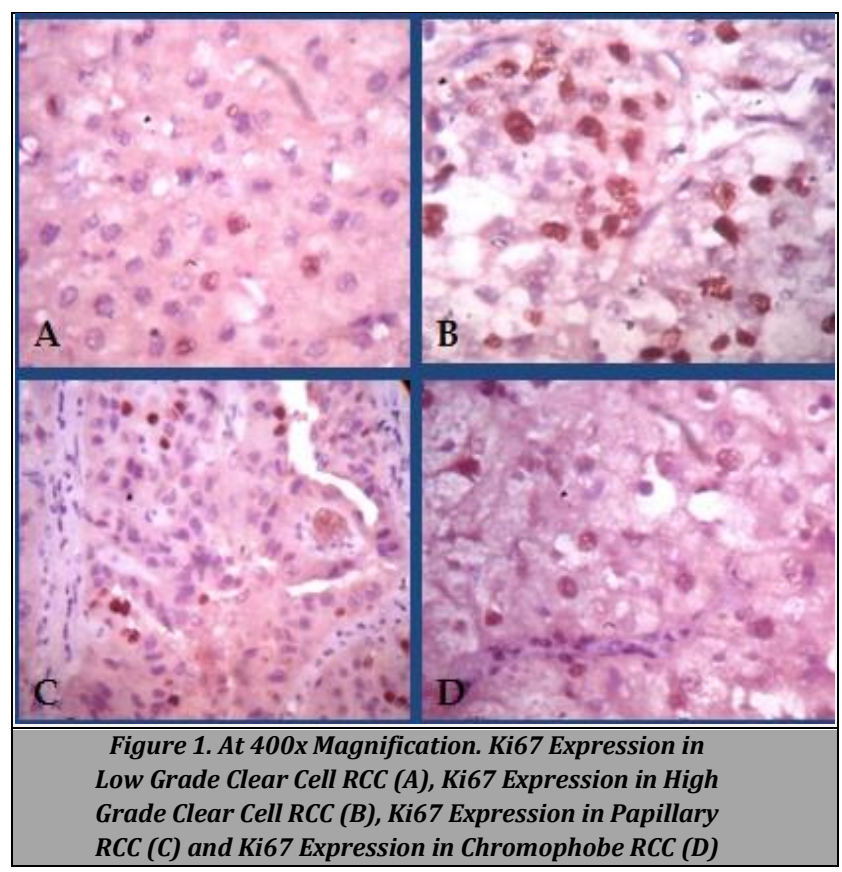




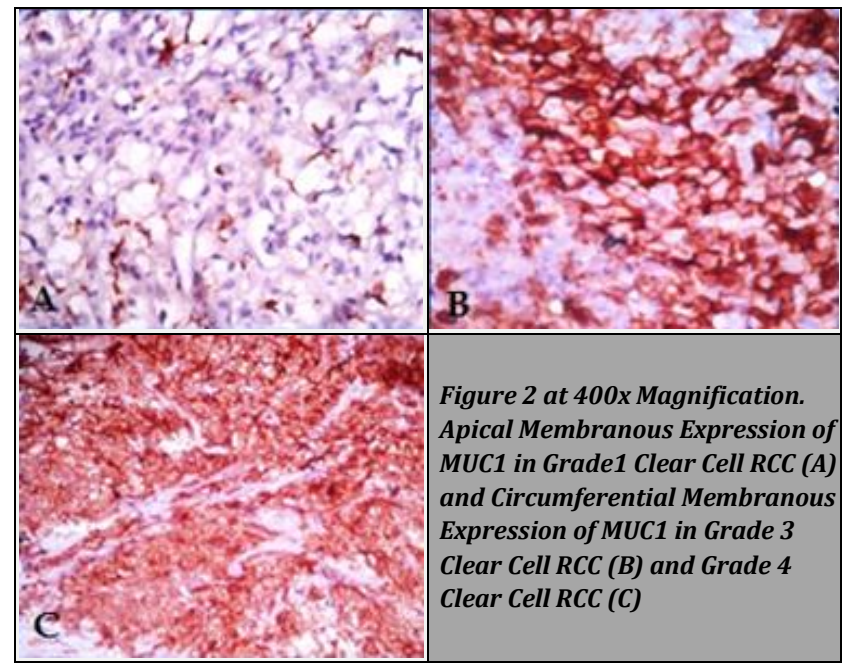

Ki67 Labelling Index in Relation to the Stage and Grade of RCC

Out of 17 stage 1 tumours, 6 cases showed Ki67 labelling index $\geq 15 \%$ and 11 cases showed Ki67 labelling index $<15$ $\%$. Out of 13 stage 2 tumours, 9 cases showed Ki67 labelling index $\geq 15 \%$ and 4 cases showed Ki67 labelling index $<15 \%$. Among the stage 3 and stage 4 cases, all the cases showed Ki67 labelling index $\geq 15 \%$. So, Ki67 labelling index increases with increase in stage of tumour which was statistically significant (P value - 0.003).

Out of 10 grade 1 tumours, 1 case showed Ki67 labelling index $\geq 15 \%$ and 9 cases showed Ki67 labelling index $<15 \%$. Out of 14 grade 2 tumours, 8 cases showed Ki67 labelling index $\geq 15 \%$ and 6 cases showed Ki67 labelling index $<15 \%$. Among grade 3 and grade 4 tumours, all the cases showed Ki67 labelling index $\geq 15 \%$. So, Ki67 labelling index increases with increase in grade of tumour which was statistically significant $(\mathrm{P}<0.00001)$ (Table 2$)$.

\section{MUC1 Expression in Relation to the Grade and Stage of Clear Cell RCC}

MUC1 immunoreactivity of more than $10 \%$ of tumour cells was found in 28/34 clear cell RCC. When staining pattern is considered, clear cell RCC showed apical or circumferential membranous staining pattern. Among the clear cell RCC, stage of tumour ( $P$ - 0.006) and nuclear grade ( $P$ - 0.0002) showed statistically significant MUC1expression (Table 3). In clear cell RCC, apical membranous expression was found in low nuclear grade tumours (grade $1 \& 2$ ) and low stage tumours (stage $1 \& 2$ ) whereas circumferential expression was found in high nuclear grade tumours (grade $3 \& 4$ ) and high stage tumours (stage $3 \& 4$ ) (Figure 2).

\section{DISCUSSION}

Renal cell carcinoma is the most common urological malignancy with an unpredictable clinical course ${ }^{2}$.Among the urological malignancies, it has the poorest prognosis. ${ }^{13}$ Prognosis of tumours with same histological type and stage varies between patients to patient. In RCC, nuclear grade and tumour stage are the two important factors that can predict the prognosis of tumour. The most commonly followed nuclear grading system was Fuhrman grading system. This system often shows inter observer and intra observer variation. ${ }^{14}$ With the advent of targeted therapies, many studies were performed with immunohistochemistry markers to predict the prognosis, for treatment planning and follow up.

Ki67 is a marker of active cell proliferation. In many studies, there was a significant association between the Ki67 index and RCC patient's survival. ${ }^{7}$ In our study, Ki67 labelling index $\geq 15 \%$ is seen in $70 \%$ of cases and this was correlating with the study done by Amouian et al. ${ }^{15}$ among 30 cases with $66.6 \%$ positive for Ki67. The positive expression rate of Ki67 was $47.7 \%$ in the study done by Kaizheng et al. ${ }^{16}$ which included 1239 cases. $53.7 \%$ expression was found in the study done by SezenKocarsian ${ }^{17}$ which include 67 cases of RCC.

In our study, Ki67 expression was in correlation with nuclear grade and this was similar to the study done by Muhammad Zain Mehdi,13 Matthew H. T Bui et al. ${ }^{7}$ Kaizheng et al.16 and Amouian et al. ${ }^{15}$ In our study, Ki67 expression has significant correlation with stage of tumour and this was similar to the study done by Kaizheng et al. ${ }^{16}$ Onda $\mathrm{H}$ et al. ${ }^{18}$ and Bidisha Chakraborty et al. ${ }^{3}$ There was no significant correlation between Ki67 expression and histological subtypes.

MUC1 is a trans membrane mucin protein which belongs to the human mucin family expressed by the epithelial cells. In case of its abnormal expression, there will be circumferential type expression in tumour cells and such expression pattern is suspected to destabilise cell to cell adhesion, thereby favouring metastasis. In our study, MUC1 immunoreactivity of more than $10 \%$ of tumour cells was found in 28/34 clear cell RCC. Among the clear cell RCC in our study, nuclear grade of tumour showed statistically significant MUC1 expression ( $\mathrm{P}=0.0002)$, with low grade tumours showing apical membranous type expression and high grade tumours showing circumferential membranous type expression. Among the clear cell RCC in our study, stage of tumour $r$ also showed statistically significant MUC1 expression $(P=0.006)$, with low stage tumours showing apical membranous type expression and high stage tumours showing circumferential membranous type expression. This was correlating with the study done by Cord Langer et al. ${ }^{9}$ They found statistically significant MUC1 expression with tumour stage $(P$ - 0.002) and nuclear grade $(P$ - 0.0001), when staining pattern is considered, with low stage and low grade tumours showing predominantly apical membranous staining pattern whereas high stage and high grade tumours showing predominantly circumferential membranous expression. Similarly, MUC1 expression showed statistically significant correlation with nuclear grade $(\mathrm{P}<0.005)$ among 44 pT1Clear cell RCC cases in the study done by Xavier Leroyet al. ${ }^{19}$ Again, in the study done by Fujita et al..$^{20}$ among 51 cases of clear cell RCC, they observed that the low grade tumours show less MUC1 staining than high grade tumours and metastatic tumours show more MUC1 staining than the localised tumours.

In our study, MUC1 expression was studied only in clear cell RCC and so more studies with other histological types should be carried out to evaluate correlation of nuclear grade 
and stage with MUC1 expression in other histological types of RCC.

\section{CONCLUSIONS}

High Ki67 labelling index in renal cell carcinoma is seen to correlate with higher nuclear grade and stage of tumour. High level expression with circumferential staining pattern of MUC1 is seen in high grade tumours with increased risk of metastasis. So MUC1 and Ki67 can be considered as a marker of prognosis of RCC. Further, large studies with multivariate analysis should be done to demonstrate MUC1 as a prognostic marker and as a therapeutic target for RCC.

Data sharing statement provided by the authors is available with the full text of this article at jemds.com.

Financial or other competing interests: None.

Disclosure forms provided by the authors are available with the full text of this article at jemds.com.

\section{REFERENCES}

[1] Stinga AC, Stinga AS, Simionescu C, et al. Histopathological study of renal cell carcinoma. Curr Health Sci J 2009;35(1):50-5.

[2] Celik EZ, Avunduk MC. Correlation of mean nuclear major diameter based nuclear morphometry assessed by image analysis system and fuhrman nuclear grading with clinicopathologic prognostic parameters in renal cell carcinoma. Eur J Basic Med Sci 2013;3(3):44-9.

[3] Chakraborty B, Sarkar P, Bhattacharya P. Correlation of vascular endothelial growth factor and KI-67 expression with histological grade and stage of renal cell carcinoma. Journal of Evolution of Medical and Dental Sciences 2019;8(10):706-11.

[4] Pramanik S, Sur S, Bankuraetal B. Expression of proliferating cell nuclear antigen and Ki-67 in renal cell carcinoma in Eastern Indian patients. International Surgery Journal 2019;6(10):3687-93.

[5] Muglia VF, Prando A. Renal cell carcinoma: histological classification and correlation with imaging findings. Radiol Bras 2015;48(3):166-74.

[6] Xie Y, Chen L, Ma X, et al. Prognostic and clinicopathological role of high $\mathrm{Ki}-67$ expression in patients with renal cell carcinoma: a systematic review and meta analysis. Scientific Reports 2017;7:44281.

[7] Bui MHT, Visapaa H, Seligson D, et al. Prognostic value of carbonic anhydrase IX and Ki-67 as predictors of survival for renal clear cell carcinoma. The Journal of Urology 2004;171(6 Pt 1):2461-6.
[8] Wang Z, Xie H, Guo L, et al. Prognostic and clinicopathological value of Ki-67/MIB-1 expression in renal cell carcinoma a meta-analysis based on 4579 individuals. Cancer Management and Research 2017;9:679-89.

[9] Langer C, Ratschek M, Rehak P, et al. Expression of MUC1 (EMA) and E-cadherin in renal cell carcinoma: a systematic immunohistochemical analysis of 188 cases. Modern Pathology 2004;17(2):180-8.

[10] Hilkens J, Ligtenberg MJ, Vos HL, et al. Cell membrane associated mucins and their adhesion-modulating property. Trends Biochem Sci 1992;17(9):359-63.

[11] Eble JN, Sauter G, Epstein JI, et al. World Health Organization classification of tumours pathology and genetics of tumours of the urinary system and male genital organs. Lyon, France: IARC Press 2004: p. 9-87.

[12] Edge SB, Compton CC. The American Joint Committee on Cancer (AJCC): the 7th edition of the AJCC cancer staging manual and the future of TNM. Ann Surg Oncol 2010;17(6):1471-4.

[13] Mehdi MZ, Nagi AH, Naseem N. MCM-2 and Ki-67 as proliferation markers in renal cell carcinoma: a quantitative and semi-quantitative analysis. International Braz J Urol 2016;42(6):1121-8.

[14] Bektas S, Barut S, Kertis G, et al. Concordance of nuclear morphometric analysis with Fuhrman nuclear grade and pathologic stage in conventional renal cell carcinoma. Turkish Journal of Pathology 2008;24(1):14-8.

[15] Amouian S, Farzadnia M, Memar B, et al. Expression of P53 and Ki67 proteins in renal cell carcinoma and its relationship with nuclear grade. Iranian Journal of Pathology 2008;3(1):25-9.

[16] Zheng K, Zhu W, Tan J, et al. Retrospective analysis of a large patient sample to determine p53 and Ki-67 expressions in renal cell carcinoma. J BUON 2014;19(2):512-6.

[17] Kocarslan S, Guldur ME, Ekinci T, et al. Comparison of clinicopathological parameters with FoxM1 expression in renal cell carcinoma. J Cancer Res Ther 2014;10(4):1076-81.

[18] Onda H, Yasuda M, Serizawa A, et al. Clinical outcome in localized renal cell carcinomas related to immunoexpression of proliferating cell nuclear antigen, Ki-67 antigen and tumour size. Oncology Reports 1999;6(5):1039-43.

[19] Leroy X, Zerimech F, Zini L, et al. MUC1 expression is correlated with nuclear grade and tumor progression in pt1 renal clear cell carcinoma. Am J Clin Pathol 2002;118(1):47-51.

[20] Fujita K, Denda K, Yamamoto M, et al. Expression of MUC1 mucins inversely correlated with post surgical survival of renal cell carcinoma patients. Br J Cancer 1999;80(1-2):301-8. 